\title{
Underwater Explosion Response of Curved Composite Plates
}

James LeBlanc ${ }^{\mathrm{a}}$, Arun Shukla ${ }^{\mathrm{b}}$

a Naval Undersea Warfare Center (Division Newport), 1176 Howell Street, Newport, RI, 02841

${ }^{\mathrm{b}}$ University of Rhode Island, 92 Upper College Road, Kingston, RI, 02881

*Corresponding author: Telephone: (401) 832-7920

Fax: (401) 832-7207

Email: James.M.LeBlanc@Navy.mil

\begin{abstract}
The effect of plate curvature, plate thickness, and thickness distribution on the response of curved composite plates subjected to far field underwater explosion (UNDEX) loading has been studied through computational simulations. In this study five panels with increasing radii of curvature are considered. Furthermore, the effect of plate thickness is considered by investigating three plate thicknesses for a given radii of curvature. Finally, a comparison is made between a plate with a uniform thickness and a plate with equal mass but a thicker outer boundary and thinner midsection. The effects are assessed using the plate center point deflection, full field deformation evolution, and fluid structure wave interaction. The results show that when subjected to shock pressure loading the deformation mechanics of the plate is significantly affected by the amount of curvature, thickness, and thickness distribution.
\end{abstract}

Keywords: Composite Materials; Composite Damage; Underwater Explosion; Plate Curvature; Finite Element Modeling;

\section{Introduction}

The use of composite materials is becoming increasingly prevalent in a wide variety of structural applications including ship hull designs, advanced airframes, and military ground vehicles. The advantages of composite materials include high specific strengths, greater design 
flexibility, improved corrosion resistance, and overall reduced maintenance costs. However, the use of these materials in a military environment requires that they be able to survive extreme loading conditions including ballistic and shock events. Utilization of these materials in naval applications subjects them to the specific risk of the exposure to underwater explosion (UNDEX) events. The response of composites under shock loading conditions has recently been investigated utilizing both experimental and computational methods. However the level of understanding of the response of these materials at these high loading rates is not as established as that under static conditions. When shock loading is a concern, this typically results in the conservative design of composite structures leading to overdesigns which do not afford the full weight advantage afforded by these advanced materials.

Composite materials subjected to highly transient loading conditions experience damage in the form of distinct mechanisms including fiber breakage, matrix cracking, and inter-laminar delamination. A large number of studies, both experimental and computational, have been performed on composite materials subjected to highly transient loading conditions in order to study these damage mechanisms and associated evolution. Studies on shock loading of composite materials have examined the material response over a range of loading rates. Tekalur et al [1] investigated the effects of blast loading on both E-Glass and Carbon based laminates through the use of a small scale explosion tube to consider the shock load combined with the effects of the heat generated during combustion of the explosive materials. Mourtiz has studied the effect of shock loading on the flexural [2] and fatigue [3] properties of composite laminates when subjected to underwater shock loading. LeBlanc et al studied the effects of shock loading on composites subjected to UNDEX loading through computational and experimental methods $[4,5]$. Work by Latourte et al [6] utilized a scaled fluid structure method [7] to study the failure 
modes and damage mechanisms in both monolithic and sandwich plates subjected to underwater impulsive loads. Schiffer and Tagarielli [8] utilized a transparent shock tube coupled with high speed photography and numerical simulations to investigate the response of circular composite plates including plate deformation mechanisms and caviation development. The effects of underwater explosion bubbles on the response of a stiffened composite hull structure has been studied by Gong and Khoo [9] through a combined boundary element and finite element method. Wei et al [10] have developed a fluid-structure interaction model to study both monolithic and sandwhich composite plates subjected to underwater blast loading and found that there is a strong strain rate sensitivity on the overall damage evolution of the panels, specifically delaminations. The use of three-dimensional fiber architectures to improve the shock response of composite laminates through the use of through thickness fibers has been investigated experimentally and numerically. Pankow et al [11] utilized an air driven shock tube to study the effect of shock loading on 3D composites in terms of damage mechanisms and transient response. The results of the study indicate there is likely an optimal Z-direction fiber content to reduce damage and maximize panel stiffness. A corresponding computational study [12] was shown to accurately simulate the experimental results.

Due to the complexity of many advanced structural designs, curved plates are common. The complexity of these geometrical designs results in structural responses that are significantly different from flat panels, specifically when subjected to transient loading conditions such as shock. Kumar et al investigated the effect of panel curvature on both aluminum [13] and carbon composite [14] panels through the use of air driven shock tube and found that as the radius of curvature is decreased (sharper curvature) the plate sustains localized central damage rather than overall plate flexure. Saghafi and al [15] investigated the effect of preload on the impact 
response of singly curved composite panels and found that while there was an increase in damage with increasing preload, there was a decrease in overall energy absorption and plate deflections.

The objective of this study is to investigate the effect that plate curvature has on the deformation mechanics and fluid structure interaction of doubly curved composite panels subjected to underwater explosive loading conditions. This is accomplished by extending a previously developed finite element model, which was validated to test data, to account for varying levels of plate curvature and evaluating the plate response.

\section{Composite Material Model}

The composite material used in the simulations presented in this paper is an E-Glass / Vinyl ester composite with a $0^{\circ}-90^{\circ}$ biaxial layup. The glass fabric is a balanced construction of $0^{\circ}$ and $90^{\circ}$ fibers with the two layers being stitched together rather than woven. This material was utilized in the experimental work [5] which serves as the foundation for the current study. The panels consist of 3 plys of the fabric, with each ply oriented in the same direction, i.e. the $0^{\circ}$ fibers in each ply are parallel. The plates have a total thickness of $1.37 \mathrm{~mm}(0.054 \mathrm{in}$.$) and a$

fiber content of $62 \%$ by weight. The material properties are listed in Table 1 and were previously determined through testing per ASTM specifications.

\section{Panel Configurations}

\subsection{Curvature Configurations}

This study examines the effect of plate curvature by varying the panel geometry from shallowly curved to a near hemisphere. The measure of curvature is taken to be the angle 
between the vertical axis and the line of tangency with respect to the vertical axis, Figure 1.

Using this measure, the shallowest plate curvature has an angle of tangency of $75^{\circ}$ and the most highly curved plate has an angle of $15^{\circ}$. In the current investigation, 5 plate curvatures are chosen with angles of tangency ranging from $15^{\circ}$ to $75^{\circ}$ in $15^{\circ}$ increments as shown in Figure 2. In all cases the plates are oriented such that the shock pressure load acts on the convex face of the plate.

\subsection{Thickness Configuration}

In addition to the plate curvatures discussed in the prior section, the effect of thickness on the shock response of curved composite panels has been investigated through 2 methods. In the first approach, the overall panel thickness was uniformly increased by $25 \%$ and $50 \%$ for an overall panel thickness of $1.71 \mathrm{~mm}$ and $2.05 \mathrm{~mm}$ respectively. This results in plates which are also $25 \%$ and $50 \%$ heavier as compared to the $1.37 \mathrm{~mm}$ baseline panel. The second approach utilizes a redistribution of material to the outer edge of the plates with a corresponding thickness decrease in the central region of the plate. This results in a plate which has an equivalent mass to the baseline plate, but with a thicker out ring of material. The thicker ring of material is indicated by the grey color in Figure 4, with the reduced thickness central region indicated by blue. This thicker region in the plate configuration is $1.83 \mathrm{~mm}$ (33\% increase from baseline of $1.37 \mathrm{~mm}$ ) and through the conservation of overall panel weight the central region is $1.02 \mathrm{~mm}$. The goal of this panel configuration was to determine if the overall panel inversion process could be arrested by preventing the formation of a hinge at the boundary (see deformation mechanics discussion below). For each panel configuration, only the $45^{\circ}$ curvature is evaluated to determine the meaningful trends. 


\section{Conical Shock Tube}

The experimental results which act as the validation for the computational model were obtained through the use of a conical shock tube (CST) facility located at the Naval Undersea Warfare Center, Division Newport. Although the tube is not utilized in the current study, the UNDEX pressure loading from the experiments is used to drive the models and thus a brief overview is provided for background [Full details are found in [5]]. The shock tube is a horizontally mounted, water filled tube with a conical internal shape, Figure 4 . The tube geometry represents a solid angle segment of the pressure field that results from the detonation of a spherical, explosive charge. In the shock tube the rigid wall acts to confine the expansion of the pressure wave in a manner that simulates a conical sector of the free field pressure field. The pressure shock wave is initiated by the detonation of an explosive charge at the breech end of the tube which then proceeds down the length of the tube. The pressure profile obtained from the experiments and utilized in the current computational study is shown in Figure 5. This profile was obtained using a M6 Blasting Cap $-1.32 \mathrm{~g}(.00292 \mathrm{lb})$ TNT Equivalency and is measured $0.508 \mathrm{~m}$ ( $20 \mathrm{in}$.) from the face of the test specimen. The length of the tube is sufficient so that plane wave conditions are nearly established at the test specimen.

The specimens are $26.54 \mathrm{~cm}$ (10.45 in.) in overall diameter with a $22.86 \mathrm{~cm}$ (9 in.) unsupported middle section, air backed, and held with fully clamped edges. The mounting arrangement that was used in the experiments is shown in Figure 6. 


\section{Finite Element Model}

This study makes use of, and further extends, the computational models that were previously developed and correlated to experimental test data in Reference [5]. The complete finite element model is shown in Figure 7. The model consists of the internal fluid of the shock tube and the curved plate. There is no numerical damping applied to the model. The fluid within the tube is considered in the simulation so as to capture the fluid structure interaction (FSI) at the interface of the fluid and test plate. Only the first $1.01 \mathrm{~m}$ (40 in.) of the fluid extending from the test sample towards the charge location are modeled. This was deemed to be acceptable for 2 reasons: (1) the fluid is loaded with the pressure profile measured $50.8 \mathrm{~cm}$ (20 in.) from the test sample and (2) a non-reflecting boundary layer is applied at the charge side boundary of the fluid domain. The fluid is modeled with solid elements (continuum) and a null material definition which has no shear stress, allows for cavitation behavior, and must be coupled with an equation of state (EOS). Cavitation behavior is captured in the fluid model by defining a pressure cutoff value of 0 in the null material definition. A linear polynomial EOS

(*EOS_LINEAR_POLYNOMIAL) is used in conjunction with the null material definition and is linear in terms of internal energy. In the current model the $\mathrm{C}_{1}$ coefficient is defined to be the bulk modulus of the water and the remaining terms of the pressure equation $\left(\mathrm{C}_{0}, \mathrm{C}_{2-6}\right)$ are taken to be 0 . The pressure load is applied as a plane wave at the location of the test pressure transducer. The pressure profiles correspond to those measured during the testing, and a typical profile is shown in Figure 5. The simulations for this study were all performed using the LSDYNA finite element code produced by Livermore Software Technology Corporation (LSTC), Version 971 Release 7.0, run in double precision mode. The flat portion of the composite plate, corresponding to the bolting ring in the experiments, is held fully fixed in all simulations. The 
outer surface of the fluid elements is fully constrained in the radial directions to simulate the shock tube walls, although axial motion is allowed.

The model of the composite plate, Figure 8, consists of three layers of fully integrated shell elements. Each layer represents a $90^{\circ}$ and a $0^{\circ}$ combined ply with a thickness of $0.457 \mathrm{~mm}$ (0.018in.). The mid-surface of each ply is meshed and the individual shell layers are offset by the ply thickness.

The Ls-Dyna material model utilized in this work is Mat_Composite_Failure_Option_Model (Mat_059, Option=Shell). This is an orthotropic material definition capable of modeling the progressive failure of the material due to any of several failure criterion including tension / compression in the longitudinal and transverse directions, compression in the through thickness direction, and through thickness shear. Once a given failure criterion has been met the ability of the material to carry a load in that direction is eliminated. An element is only deleted once it has failed in all directions. Delamination plays a significant role in energy absorption and degradation of a composite's stiffness during impact and must be accounted for in simulation. The approach taken in this study, and previously verified [5], is to use a surface-to-surface tie break contact in the implementation of the finite element code. This contact definition ties the nodes between plys together rather than making them equivalent. This inhibits relative sliding until the normal or shear stress at any given node exceeds a defined failure value. Once this value is exceeded the node becomes free to slide and the contact reverts to a standard definition. This allows the slave node to separate from and/or 
slide over the master surface but does not allow it to pass through. In the current model the choice of a delamination criterion was taken to be $34.4 \mathrm{MPa}\left(5000 \mathrm{lb} / \mathrm{in}^{2}\right)$ for both tensile and shear stresses. This value represents one-half of the tensile strength of the pure resin. The degradation by $1 / 2$ of the tensile strength accounts for voids and interfacial defects / flaws between the layers of fibers during the manufacturing of the material. This value was determined by prior parametric studies as well as discussions with other experts in this field.

\subsection{Validation}

The model and methodology presented in this study has been shown to be able to accurately capture both the transient response of the plate as well as the damage extents [5]. In the prior validation study, the $60^{\circ}$ tangency plate was specifically studied. Figure 9 shows a comparison of the transient displacement for the center point of the back face of the plates. Additional validation data including velocity and damage correlations may be found in the original paper [5]. This comparison shows that the model is able to simulate the test results for the case of the shock loaded plate with $60^{\circ}$ tangency, and as such allows the model to be extended to include plates with additional levels of curvature.

\section{Results}

For each of the five plate curvatures that are studied in this work the curvature effect is assessed using the transient plate response and fluid structure interaction. Specifically, comparisons are made between the transient center point displacement, overall panel deformation mechanics, and the interaction of the pressure wave with the plate surface.

\subsection{Deformation Mechanics (Plate Curvature Effects)}


The mechanics of the plate deformation when subjected to UNDEX loading for the $75^{\circ}$, $45^{\circ}$, and $15^{\circ}$ tangency plates are shown in Figure 10. This figure shows the pattern of deformation (Centerline cross section) for each plate for the first three ms of the simulation as well as the final structural shape. Due to the differences in curvature the total time duration of the plate response increases as the plates become more highly curved (plates with larger curvature have longer deformation time durations). From this figure it is shown that although the plates are subjected to the same incident shock front, the mechanics of the deformation behavior for the plate geometries is significantly different. For the case of the plate with a shallow radius of curvature $\left(75^{\circ}\right)$ the plate undergoes a relatively smooth inversion process. At $1 \mathrm{~ms}$, a hinge forms at the outer edge of the plate at the clamped boundary, Figure 10. This hinge then leads the deformation pattern while propagating towards the center of the plate as seen in the first column of images in Figure 10. The deformation is completed when the plate has fully inverted itself at $\sim 3 \mathrm{~ms}$. The full field inversion process for the $75^{\circ}$ plate is shown in Figure 11. The $45^{0}$ plate undergoes a similar type of deformation evolution as the $75^{\circ}$ plate, however there is a clear difference in the initial formation of the hinge at the outer boundary of the plate. In the $75^{\circ}$ plate this hinge is formed in a smooth manner whereas in the $45^{\circ}$ plate, the hinge develops in a manner representative of a buckling event. Once the edge of the plate buckles the resulting hinge then migrates towards the center of the plate, thus allowing a full inversion of the curved plate. The deformation evolution exhibited by the highly curved $\left(15^{\circ}\right)$ plate under shock loading is significantly different than that of the less shallowly curved panels. Due to the low angle of tangency at the plate boundary (Plate edge is nearly perpendicular to the clamped edge) the plate deformation is dominated by a buckling of the plate shell rather than the development of an inversion hinge as seen in the shallower plates. The mechanics of this behavior is similar to that 
of the buckling of a spherical shell under increasing hydrostatic pressure. Due to the transient nature of the shock wave loading, the applied pressure is ultimately removed from the shell surface before full collapse of the shell is achieved as would be seen in a hydrostatic case. The sharp angle of the plate wall with respect to the clamped boundary precludes the formation of the hinge as the material is not able to "pop through" on itself. The final shape of each plate at the completion of the simulations is shown in Figure 12. From this figure the transition between a fully inverted deformation mechanism and a buckled plate shell is evident as occurring at plate curvatures between $45^{\circ}$ and $30^{\circ}$. Both the $30^{\circ}$ and $15^{\circ}$ plates exhibit a buckled mode shape, with the $30^{\circ}$ plate experiencing further progression of the collapse than does the $15^{\circ}$ plate. The $45^{\circ}$ plate does exhibit a fully inverted final shape, although as previously noted, the initial formation of the inversion hinge is the result of a localized buckle as opposed to the smooth formation seen in the $75^{\circ}$ and $60^{\circ}$ plates.

The time history of the center point deflection for each of the respective panels is shown in Figure 13. From this figure it is seen that the rate at which the panel inversion process progresses is influenced by the level of curvature of the plates. The speed at which the center point deflects during the inversion process is slower as the panel curvature is increased. The $75^{\circ}$ panel experiences the largest center point velocity (as indicated by the steeper slope of the displacement curve) while the $45^{\circ}$ panel exhibits the slowest center point velocity (for the three panels which fully invert). Although the $30^{\circ}$ and $15^{\circ}$ panels do not fully invert, but rather experience a buckling deformation which is subsequently arrested, the panel center point velocities are initially consistent with those experienced by the $45^{\circ}$ plate. The $75^{\circ}, 60^{\circ}$, and $45^{\circ}$ plates all undergo a maximum center point deflection corresponding to two times that of the perpendicular distance between the center point and the clamped edge plane. The velocity 
reduction corresponding to the increasing plate curvature is indicative of an effective stiffness increase as a result of the curvature. Thus as the plate curvature is increased, the plate effective stiffness is also increased even though the plate thickness and material properties are identical for each panel.

The finite element simulation of the shock tube testing allows for a visual full field representation of the interaction between the pressure wave and the composite plates. The pressure fields in the fluid as it interacts with and loads the plates, for the $75^{\circ}, 45^{\circ}$, and $15^{\circ}$ plates are shown in Figure 14. In order to provide a more meaningful comparison of the fluid structure interaction for each of the plate curvatures, time zero is taken to be the arrival of the shock pressure front at the plate. Due to the differences in plate curvature this time zero is different for each plate simulation, with the wave arriving at the $15^{\circ}$ plate earlier in the simulation due to its further extension into the fluid domain. Figure 14 illustrates several key points related to the effect of curvature on the loading of curved plates where the decay length of the shock front is small $(0.145 \mathrm{~ms})$ [Decay length is taken to be the time duration for the pressure to decay from its peak, $\mathrm{P}_{\max }$, to $\left.\mathrm{P}_{\max } / \mathrm{e}\right]$. First, although the pressure wave is uniform prior to its impact with the test plate, the loading on the plate itself is significantly influenced by the relative depth of the curved plate with respect to the decay length of the pressure front. In the case of the shallowly curved $75^{\circ}$ plate the shock front initially acts as a near uniform loading over the surface of the plate ( $\mathrm{t}=20 \mu \mathrm{s})$. Conversely, for the case of the highly curved $15^{\circ}$ plate the plate depth with respect to the decay length of the shock front is sufficiently narrow such that the forward portion of the plate is initially loaded by the shock front, while the portion of the plate near the clamped boundary is unloaded. As the wave continues to propagate forward the remainder of the plate is 
subsequently loaded (see $40 \mu$ s figure). However, while the wave continues to propagate over the curved plate, there is a corresponding reflection of the wave from the forward apex of the plate. Thus for the highly curved plate there is a simultaneous loading scenario in which the shock front is reflected from the forward apex of the plate while the initial shock front continues to envelop the remainder of the plate. The $45^{\circ}$ degree plate exhibits a similar loading evolution as the $15^{\circ}$ plate although the time delay between initial loading of the front face and the clamped edge is smaller due to the reduced depth of the plate with respect to the shock front decay length. In addition to the curvature effects on the incident loading of the plates, there is a significant influence of the plate curvature on the reflection of the incident wave. For the case of the shallowly curved plate $\left(75^{\circ}\right)$ it is seen that subsequent to arrival of the incident wave there is the formation of a significant low pressure region $(60 \mu \mathrm{s})$ acting over the face of the plate. This low pressure region indicates the manner in which the pressure wave is reflected from the plate. The shallow curvature of the plate offers relatively low resistance to the formation of the deformation hinge originating at the plate edge (see prior discussion). Due to the low deformation resistance the reflection of the pressure wave is analogous to the reflection of a stress wave from a free surface in which a compressive wave is reflected in the form of a tensile wave. Due to the inability of a fluid to transmit tensile waves, there is the formation of a cavitation region at the plate/fluid surface as indicated by the low pressure region. Conversely, as the curvature of the plate is increased, there is a significant increase in the ability of the plate to resist the initiation of plate inversion (see prior buckling discussion). This increased resistance to inversion results in a plate which is stiffer and thus the wave reflection is similar to the reflection of a stress wave from a rigid surface, although the stiffness of the plate is not fully rigid. Due to the increased stiffness of the plate surface there is a partial reflection of the pressure wave in the form of a 
positive pressure region on the surface of the plate $(60,80 \mu \mathrm{s})$. As the plate is not fully rigid there is still some cavitation which develops on the surface of the plate, although the extent is less than that for the shallowly curved plate. Finally it is observed that for all plate curvatures there is a distinct separation of the time duration for which the pressure wave acts over the plate surface and the corresponding plate deformation. Where the pressure wave interacts with the plate over $0.1 \mathrm{~ms}$, the plate does not start to deform until the wave is nearly fully reflected and takes between 2 and $10 \mathrm{~ms}$ to complete, Figure 13.

\subsection{Thickness Effects}

The center point time history for each of the three plate thicknesses considered $(1.37 \mathrm{~mm}$, $1.71 \mathrm{~mm}$, and $2.05 \mathrm{~mm}$ ) for the $45^{\circ}$ tangent plate are shown in Figure 15. The final deformed shape for each of the plates is correspondingly shown in Figure 16. From these figures it is seen that there are two significant trends in the displacements / deformations. The first is that by increasing the plate thickness, it is possible to arrest the plate inversion process from fully progressing to a complete pop-through of the plate. However, it is also noted that for each of the plate thicknesses considered the development of a hinge originating at the plate boundary is still present. The second observation is that the relationship between final center point displacement and plate thickness is non-linear. A $25 \%$ increase in plate thickness results in a 52\% decrease in maximum center point deflection ( $90 \mathrm{~mm}$ reduced to $42.5 \mathrm{~mm}$ ). Similarly, a $50 \%$ increase in plate thickness results in a $77 \%$ decrease in center point displacement $(90 \mathrm{~mm}$ reduced to 20 $\mathrm{mm}$ ). Therefore, there is a clear tradeoff between increased plate weight (linearly related to plate thickness) and reduced panel displacement (non-linearly related to plate thickness), such that weight penalties due to the increased thickness can be outweighed by the larger reductions in 
displacement. The observed reductions in displacements are primarily due to the ability of the thicker plates to arrest the onset of plate inversion prior to completion.

\subsection{Thickness Redistribution Effects}

The comparison of the center point displacement history and physical deformation process/mechanics between the baseline $1.37 \mathrm{~mm}$ uniform plate and the equally weighted plate with a thicker outer boundary are shown in Figure 17 and Figure 18. From these figures it is shown that there is a clear difference in the manner in which the deformation evolves through time. Comparison of the center point displacement histories in Figure 17 show that the plate which has a thinner midsection achieves larger central velocities, as indicated by the steeper slope of displacement curve, than the uniformly thick plate. Furthermore, the stepped thickness plate deforms in two primary phases, namely a rapid displacement occurring from 1 to $4.5 \mathrm{~ms}$ and followed by a slower rate of deformation from 4.5 to $10 \mathrm{~ms}$ when complete inversion is completed. Conversely, the uniformly thick plate undergoes a near constant rate of deflection throughout the inversion process. A comparison of the mechanics of the deformation evolution is presented in Figure 18. From this figure it is evident that there is a fundamental shift in the manner by which the plate deformation evolves. As previously discussed for the case of the uniformly thick plate, there is a localized buckling of the plate at the edge which leads to the formation of a hinge which travels towards the center of the plate during the inversion.

Conversely, for the plate which has a thicker outer ring and thinner mid-section the primary means of deformation is a buckling of the mid-region of the plate (see $2 \mathrm{~ms}$ image). This buckled midsection then continues to pop through on itself due to the fluid pressure and once inversion of the midsection is complete the outer edges of the plate follow. Furthermore, it is noted that for 
the stepped plate, there is an absence of the formation of the hinge at the outer edge as was seen for the uniform plate.

\section{Summary and Conclusions}

The effect of curvature on composite plates subjected to underwater explosive loading conditions has been studied through computational simulations. The simulations presented in the study are an extension of previous work in which the simulation methodology was validated against test data. The model has previously been shown to be able to simulate both the transient response and the damage evolution compared to experimental test data. The simulation results demonstrate that the amount of plate curvature affects both the mechanics of the deformation of the plate when subjected to shock loading, as well as the fluid structure interaction of the pressure wave with the plate surface. Furthermore, plate thickness and thickness distribution are shown to have an effect on both amount of displacement under shock loading as well as the mechanics of the deformation evolution.

As the plate curvature is increased (becomes more highly curved) there is a corresponding increase in the relative stiffness of the plate and increased resistance to deformation. The two shallowest curved plates in the study $\left(75^{\circ}\right.$ and $\left.60^{\circ}\right)$ plates experienced the initiation of plate inversion through the smooth formation of a hinge at the clamped boundary which subsequently propagates inward from the boundary. As the level of plate curvature is increased, the formation of the hinge is initiated by a localized buckling of the plate surface at the clamped edge. This buckling then leads to a full inversion of the $45^{\circ}$, whereas the $30^{\circ}$ and $15^{\circ}$ plates are able to arrest plate inversion while instead experiencing a buckling of the entire

plate surface. Furthermore, the curvature level of the respective plates has been shown to effect 
the interaction, and subsequent reflection, of the pressure front with the plate surface. As the curvature of the plate is increased there is a corresponding increase in plate resistance to initial deformation which alters the reflection characteristics of the pressure wave. Due to the relatively low resistance to deformation of the shallowly curved $75^{\circ}$ plate, the reflection of the pressure wave results in significant surface cavitation. As the plate curvature, and associated plate stiffness, is increased the wave is reflected primarily as a compressive wave as indicated by a positive pressure on the plate surface.

In addition to the effect of plate curvature, the effects of overall plate thickness and thickness distribution were investigated. It has been shown that there is a non-linear relationship between plate thickness and overall performance increase, namely that for a given percent increase in plate thickness there is a larger percent decrease in overall plate deflection. This is largely attributed to the ability of thicker plates to arrest the inversion process prior to completion. Furthermore, it was shown when the weight of a plate is held constant, but material is shifted towards the outer edge of the plate to inhibit the hinge formation, there is a fundamental change in the deformation mechanics of the plate. For the uniformly thick plate there is the formation of a hinge at the boundary which then propagates towards the center during inversion. However, for the plate with a thicker outer edge and thinner midsection, there is an overall buckling of the midsection which dominates the deformation history and a noticeable absence of the hinge at the boundary.

Overall, it has been shown that there is a significant influence of plate curvature, thickness, and thickness distribution on both the deformation mechanics and fluid structure interaction of curved composite plates subjected to far field underwater explosive loading.

\section{Acknowledgements}


The financial support of the Naval Undersea Warfare Center (Division Newport) Inhouse Laboratory Independent Research program (ILIR) directed by Neil Dubois is acknowledged. The support of Dr. Y.D.S. Rajapakse of the Office of Naval Research under Grant Nos. N00014-10-1-0662 (University of Rhode Island) and N00014-14-WX00730 (Naval Undersea Warfare Center, Division Newport)) is acknowledged.

\section{References}

1. Tekalur AS, Shivakumar K, Shukla A. Mechanical Behavior and Damage Evolution in EGlass Vinyl Ester and Carbon Composites Subjected to Static and Blast Loads.

Composites: Part B 2008; 39:57-65.

2. Mourtiz AP. The Effect of Underwater Explosion Shock Loading on the Flexural Properties of GRP Laminates. International Journal of Impact Engineering 1996; 18:129139.

3. Mouritz AP. The Effect of Underwater Explosion Shock Loading on the Fatigue Behavior of GRP Laminates. Composites 1995; 26:3-9.

4. LeBlanc J, Shukla A. Dynamic Response and Damage Evolution in Composite Materials Subjected to Underwater Explosive Loading: An Experimental and Computational Study. Composite Structures 2010; 92:2421-2430

5. LeBlanc, J., Shukla,A., “ Dynamic Response of Curved Composite Panels to Underwater Explosive Loading: Experimental and Computational Comparisons”, Compos. Struct. (Accepted 2011).

6. Latourte, F., Gregoire, D., Zenkert, D., Wei, X., Espinosa, H., "Failure Mechanisms in Composite Panels Subjected to Underwater Impulsive Loads", Journal of the Mechanics and Physics of Solids 2011; 59:1623-1646

7. Espinosa, H., Lee, S., Moldovan, N., “A novel fluid structure interaction experiment to investigate deformation of structural elements subjected to impulsive loading". Experimental Mechanics 2006. 46 (6), 805-824.

8. Schiffer, A., Tagarielli, VL., "The response of circular composite plates to underwater blast: Experiments and modeling", Journal of Fluids and Structures 2015; 52:130-144

9. Gong, SW., Khoo, BC., "Transient response of stiffened composite submersible hull to underwater explosion bubble", Composite Structures 2015; 122:229-238 
10. Wei, X., Tran, P., Vaucorbeil, A., Ramaswamy, R., Latourte, F., Espinosa, H., "Threedimensional numerical modeling of composite panels subjected to underwater blast", Journal of the Mechanics and Physics of Solids 2013; 61: 1319-1336

11. Pankow, M., Justusson, B., Salvi, A., Waas, A., Yen, C., Ghiorse, S., "Shock Response of 3D Woven Composites: An Experimental Investigation" Composite Structures 2011; 93:1337-1346

12. Pankow, M., Waas, A., Yen, C., Ghiorse, S., "Shock Loading of 3D Woven Composites: A Validated Finite Element Investigation" Composite Structures 2011; 93:1347-1362

13. Kumar, P., LeBlanc, J., Stargel, D., Shukla, A., "Effect of Plate Curvature on Blast Response of Aluminum Panels" International Journal of Impact Engineering 2012; 46: 74-85

14. Kumar, P., Stargel, D., Shukla, A., "Effect of Plate Curvature on Blast Response of Carbon Composite Panels" Composite Structures 2013; 99:19-30

15. Saghafi, H., Minak, G., Zucchelli, A., "Effect of Preload on the Impact Response of Curved Composite Panels", Composites: Part B 2014; 60:74-81

Table 1 - E-Glass /Vinyl Ester Biaxial Laminate -Mechanical Properties (ASTM 638)

Figure 1 - Plate Curvature Measure Defintion

Figure 2 - Plate Curvature Comparison

Figure 3 - Plate Thickness Redistribution

Figure 4 - Conical Shock Tube Schematic (not to scale)

Figure 5 - Typical Shock Tube Pressure Profile

Figure 6 - Experimental Test Setup

Figure 7 - CST Finite Element Model

Figure 8 - Finite Element Model of Composite Plate

Figure 9 - Center Point Transient Displacement Correlation [5]

Figure 10 - Plate Deformation Mechanics (Cross Section View)

Figure 11 - Plate Deformation Evolution, $75^{\circ}$ Curvature

Figure 12 - Final Plate Deformations 
Figure 13 - Plate Center-point Deflection Comparion

Figure 14 - Fluid Structure Interaction Comparison

Figure 15 - Plate Center-point Deflection - Thickness Comparison

Figure 16 - Final Deformed Shape - Thickness Comparison

Figure 17 - Plate Center-Point Deflection - Thickness Distribution Comparison

Figure 18- Final Deformed Shape - Thickness Comparison 


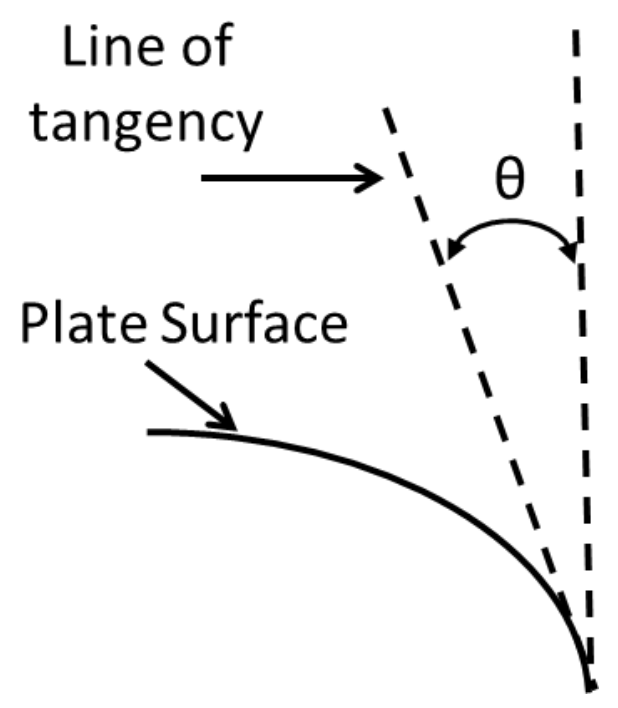

Figure 1 


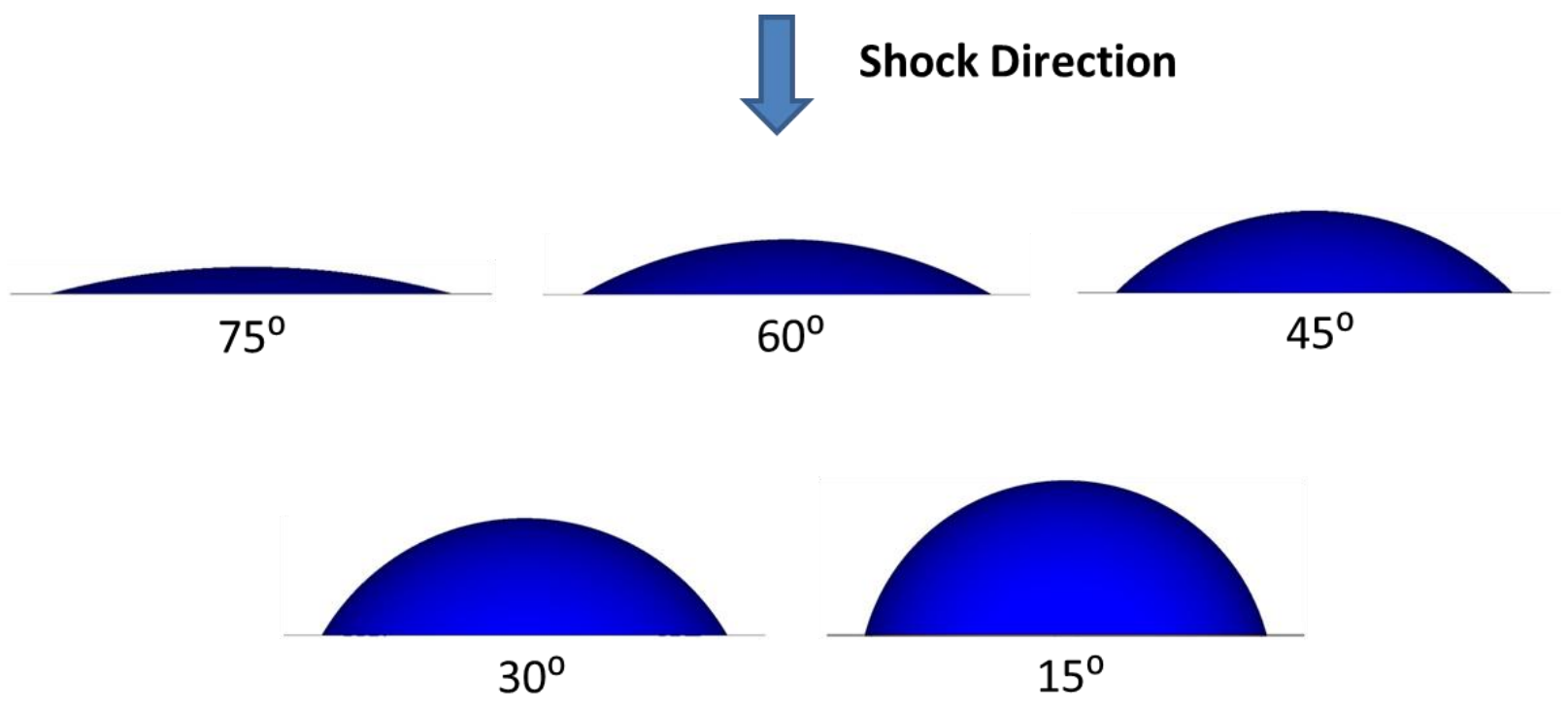

Figure 2 


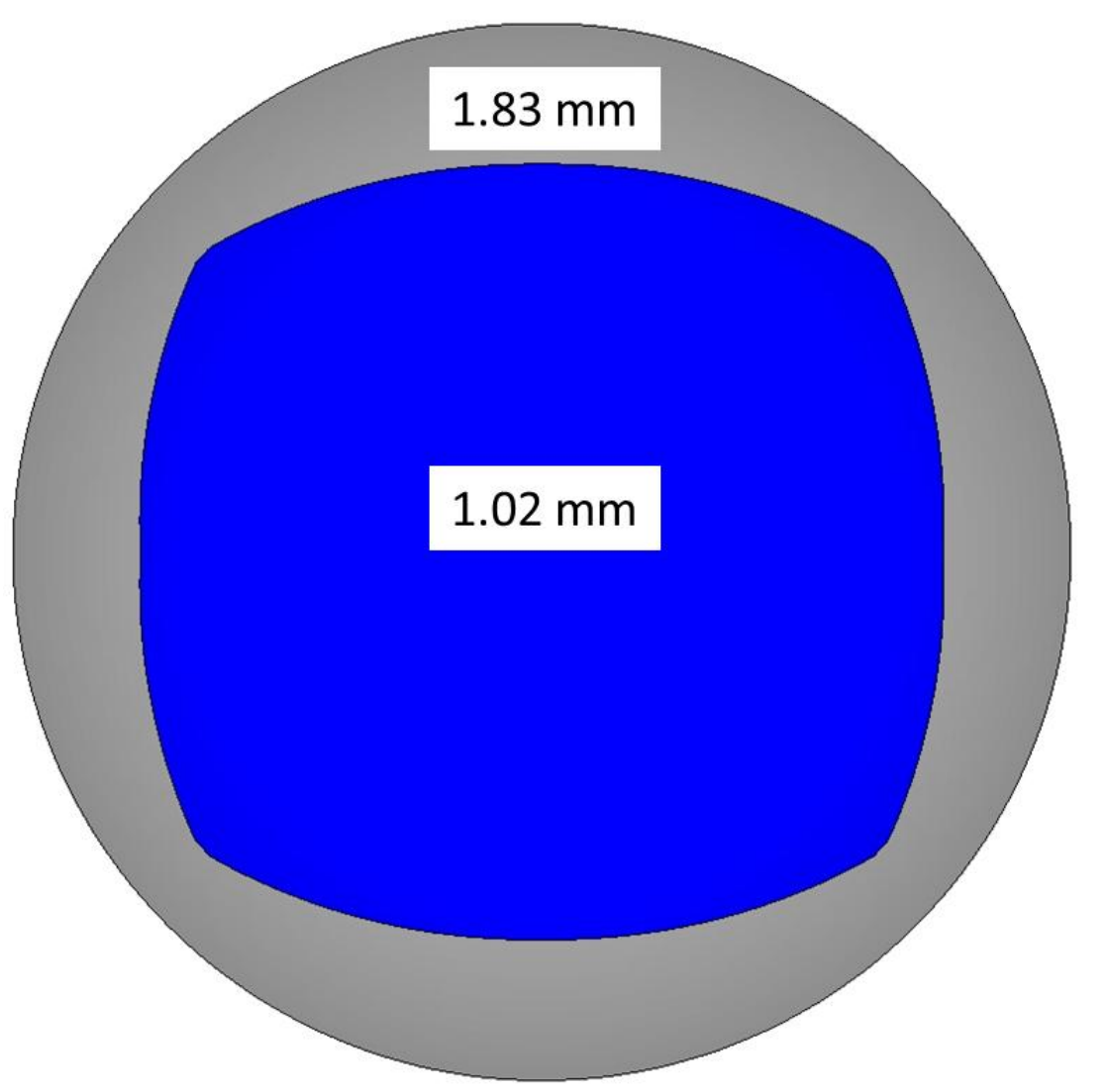

Figure 3 


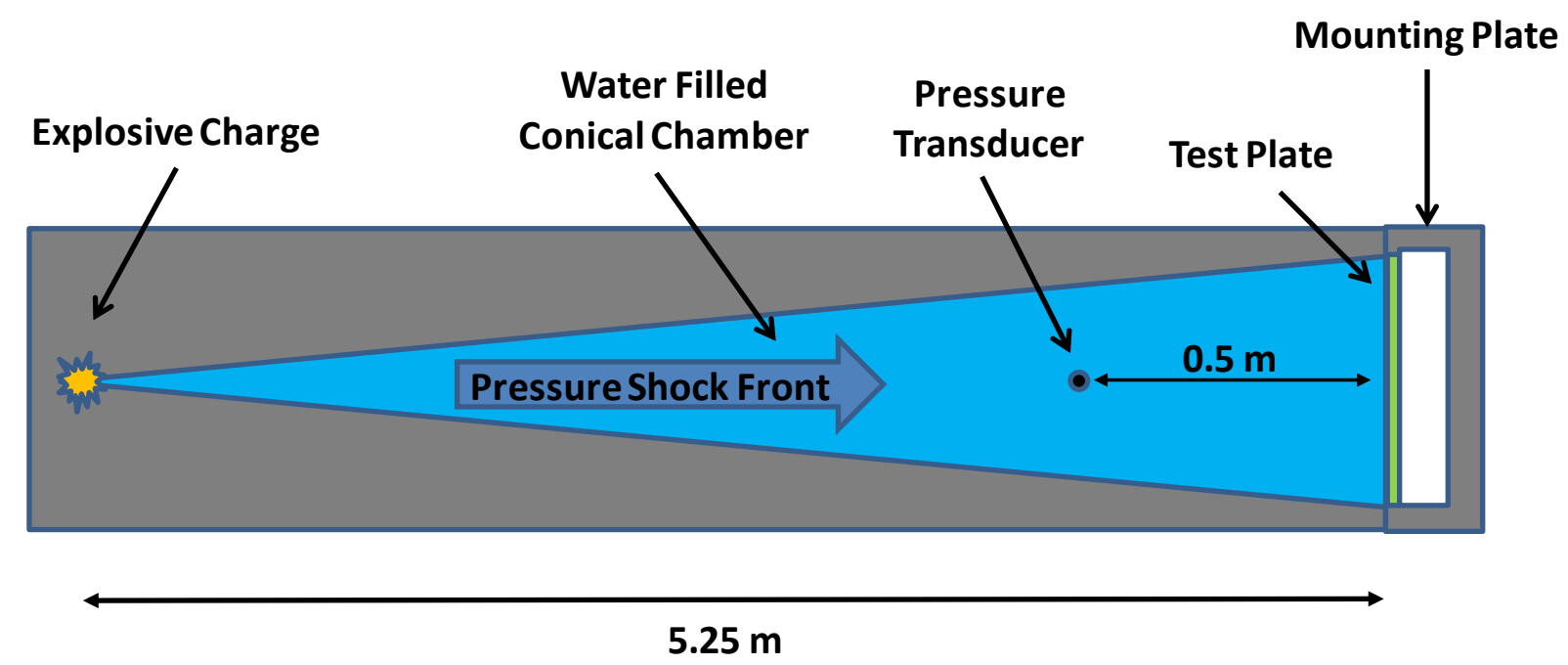

Figure 4 


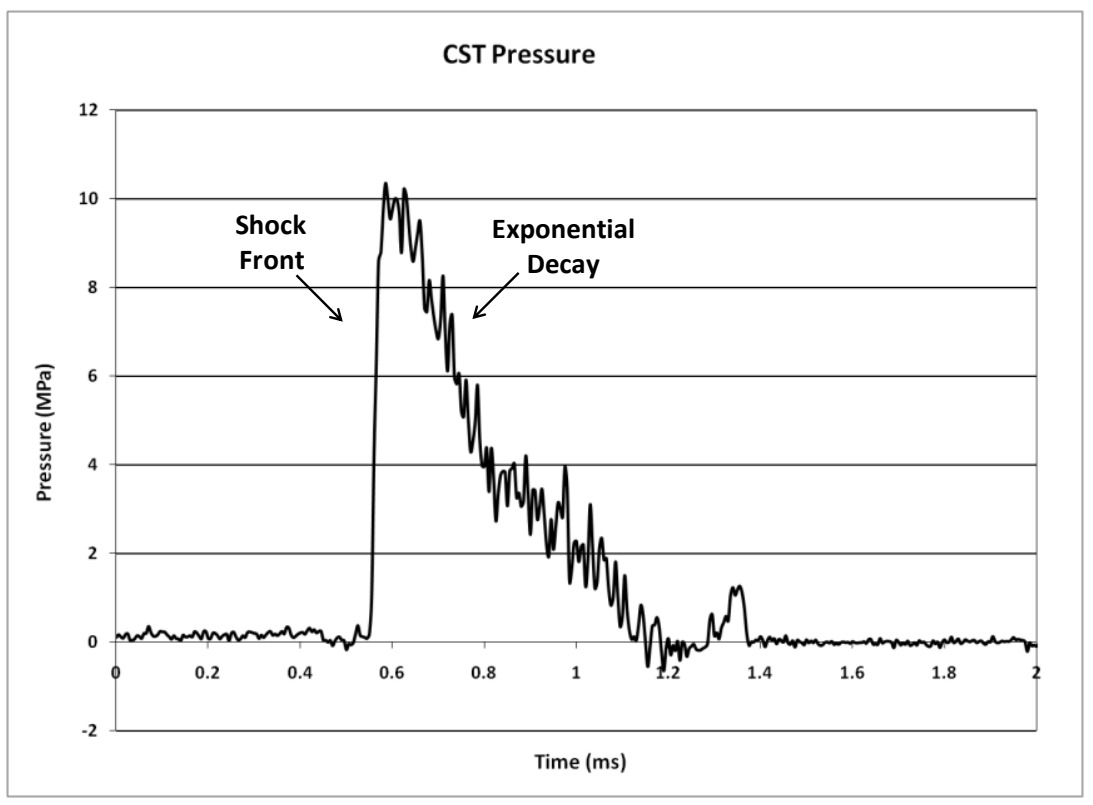

Figure 5 


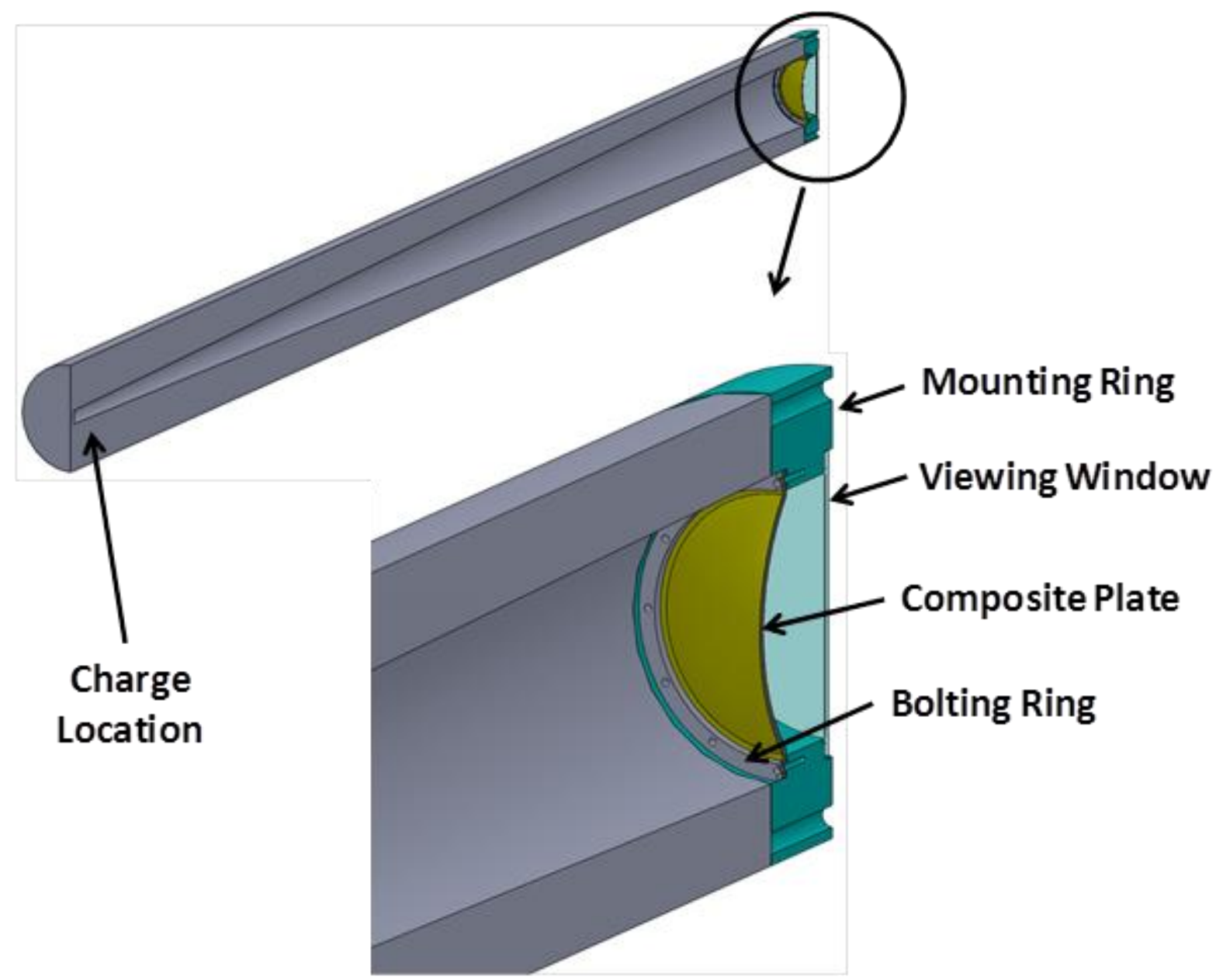

Figure 6 


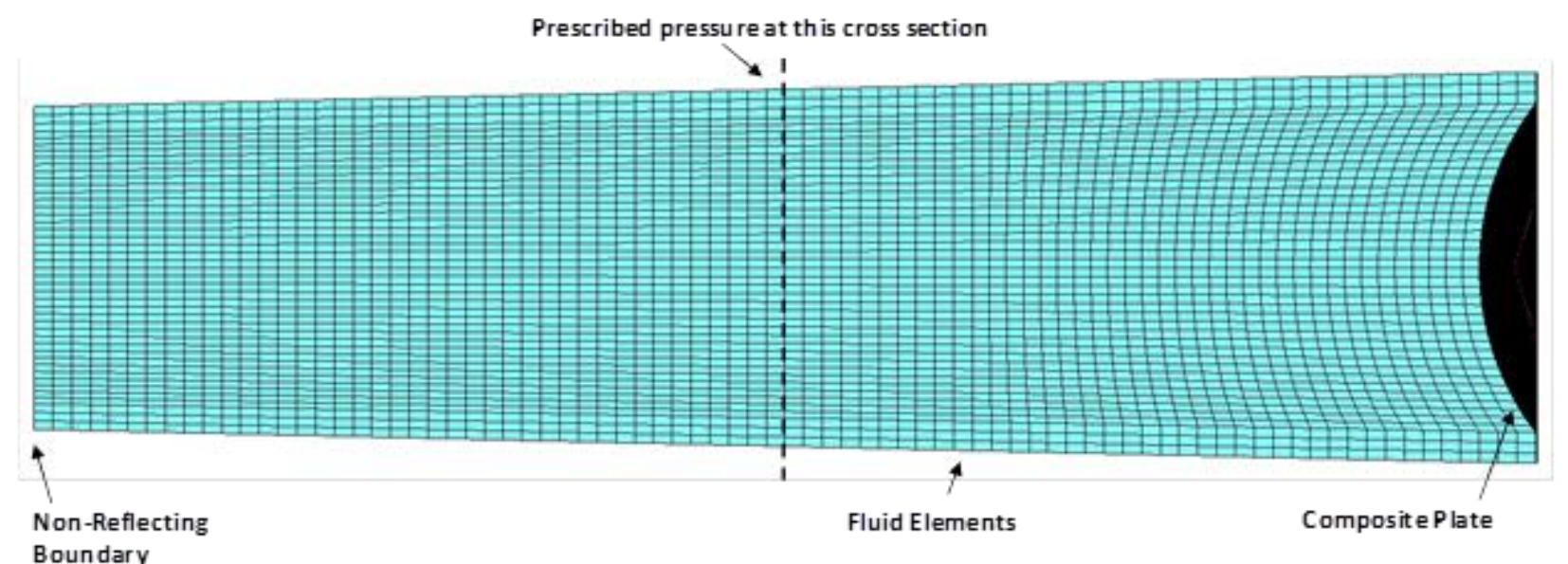

Figure 7 

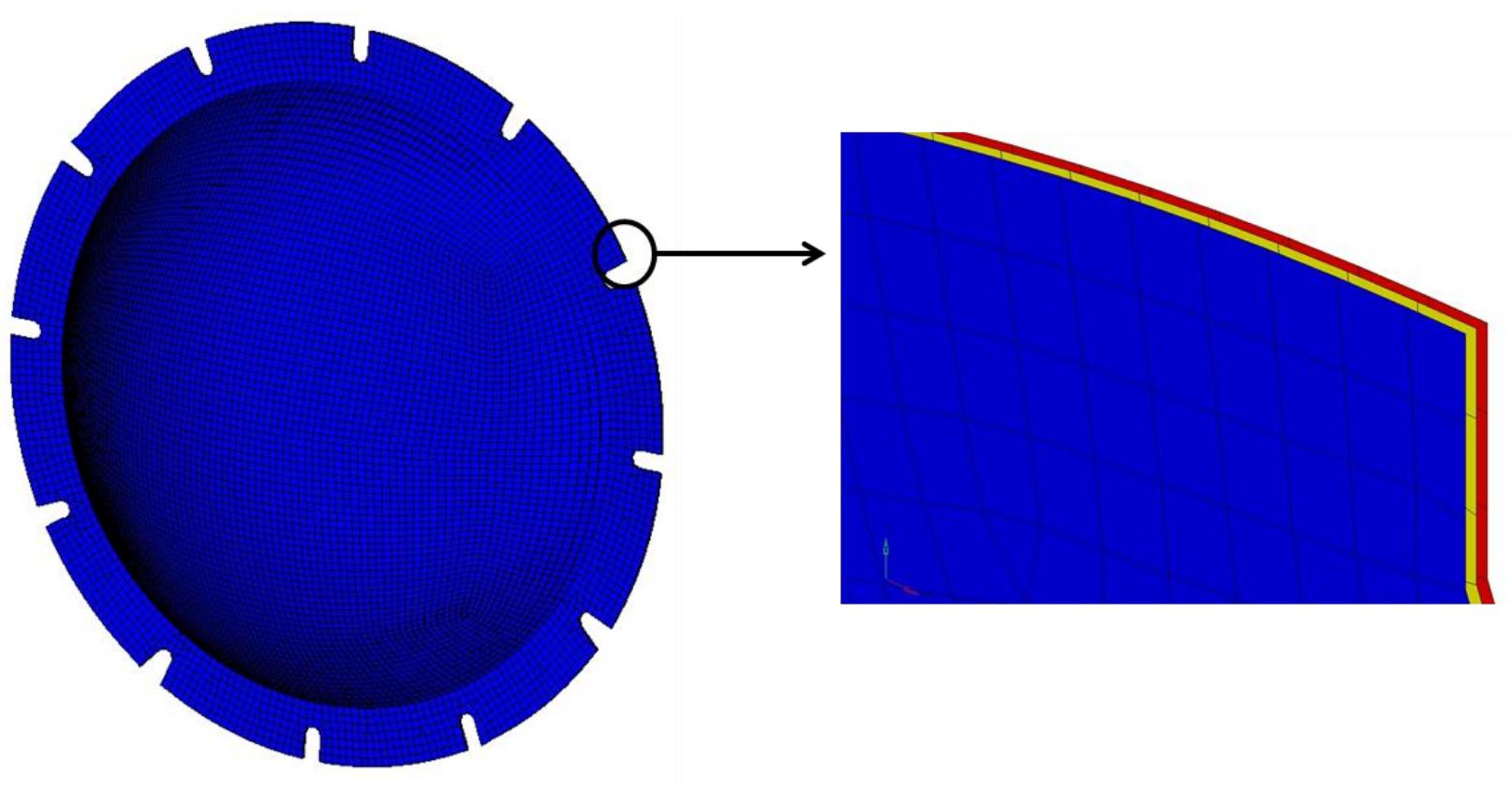

Figure 8

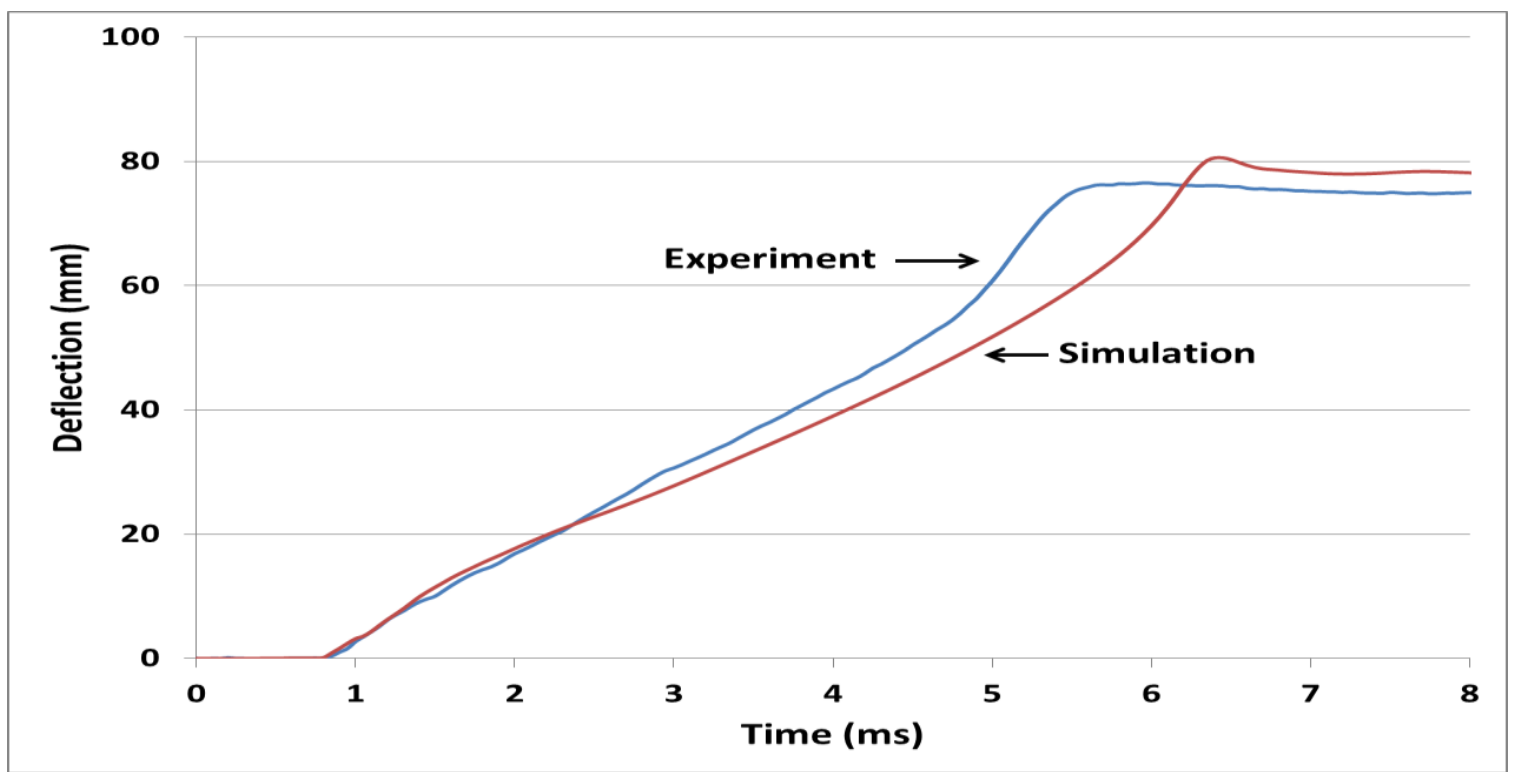

Figure 9 


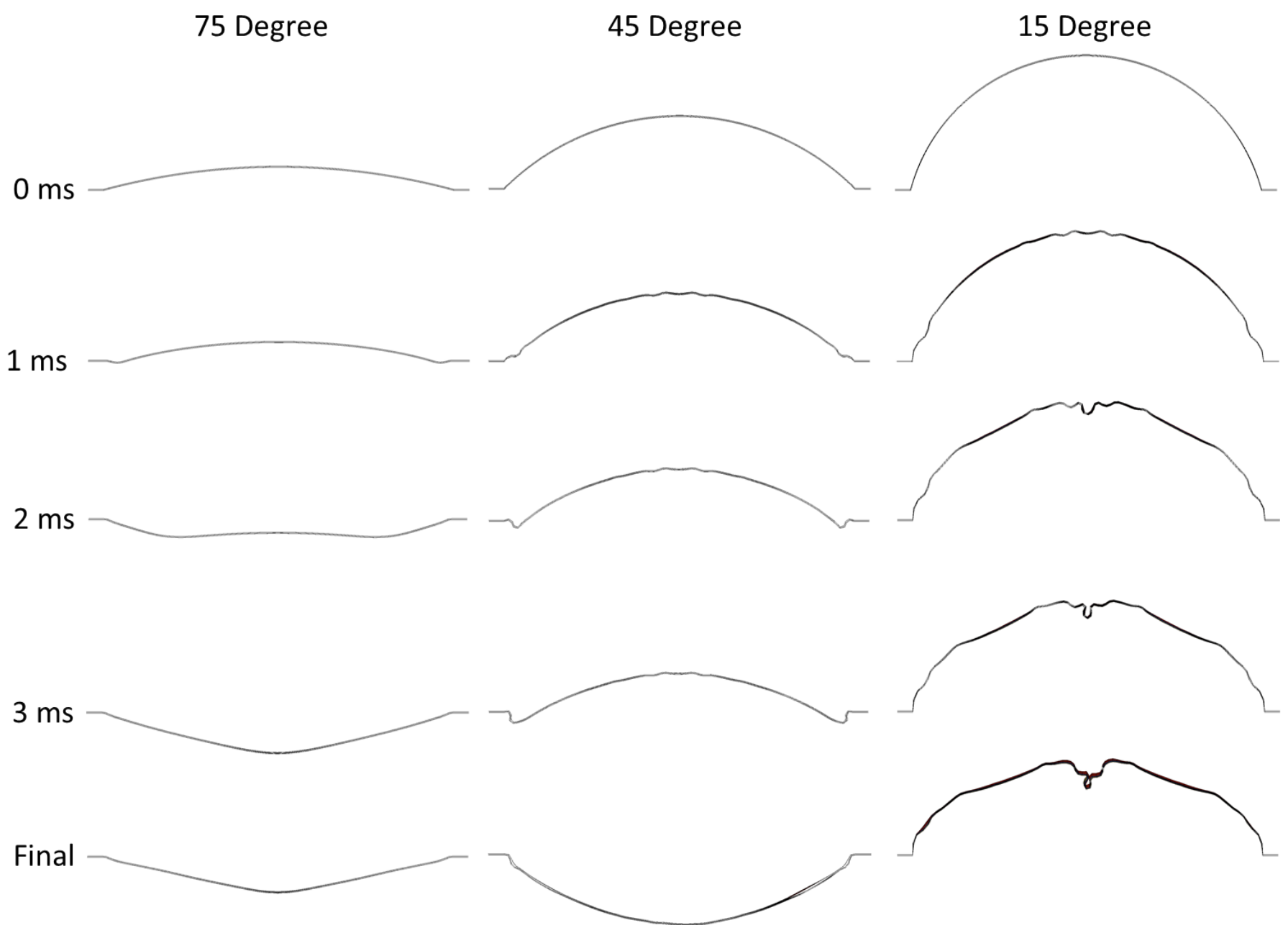

Figure 10 


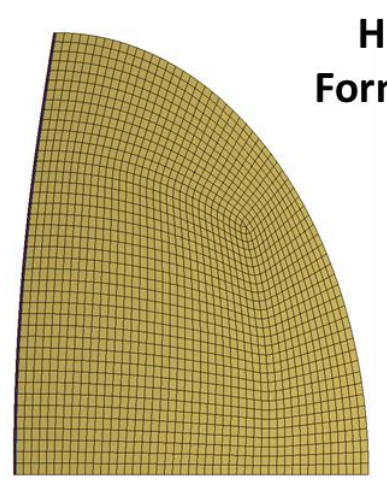

$0 \mathrm{~ms}$

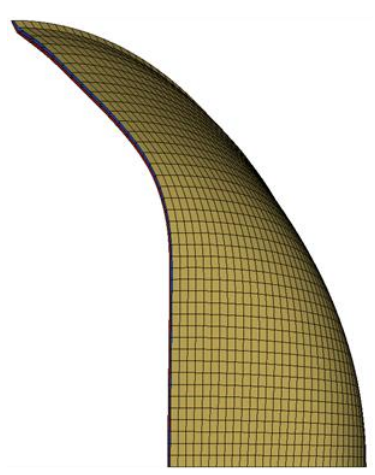

$2 \mathrm{~ms}$
Hinge

Formation

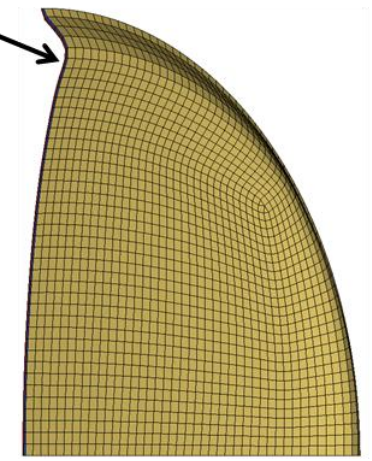

$1 \mathrm{~ms}$

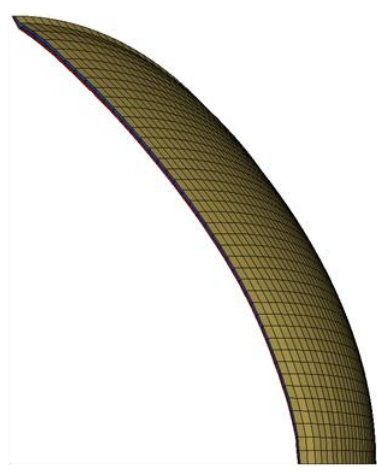

$2.5 \mathrm{~ms}$

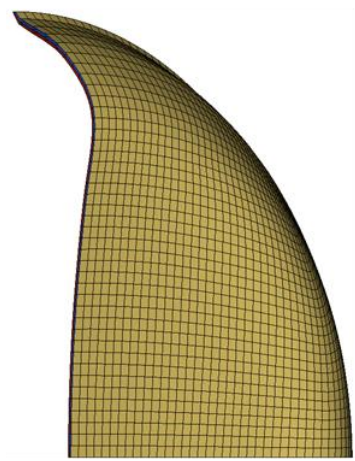

$1.5 \mathrm{~ms}$

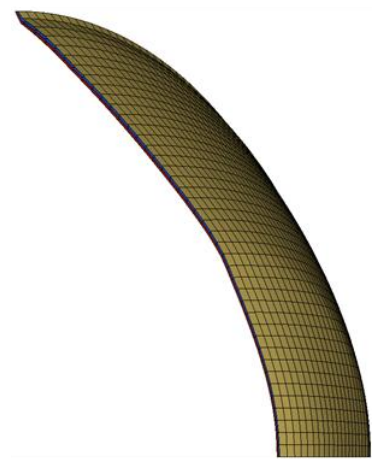

$3 \mathrm{~ms}$

Figure 11 

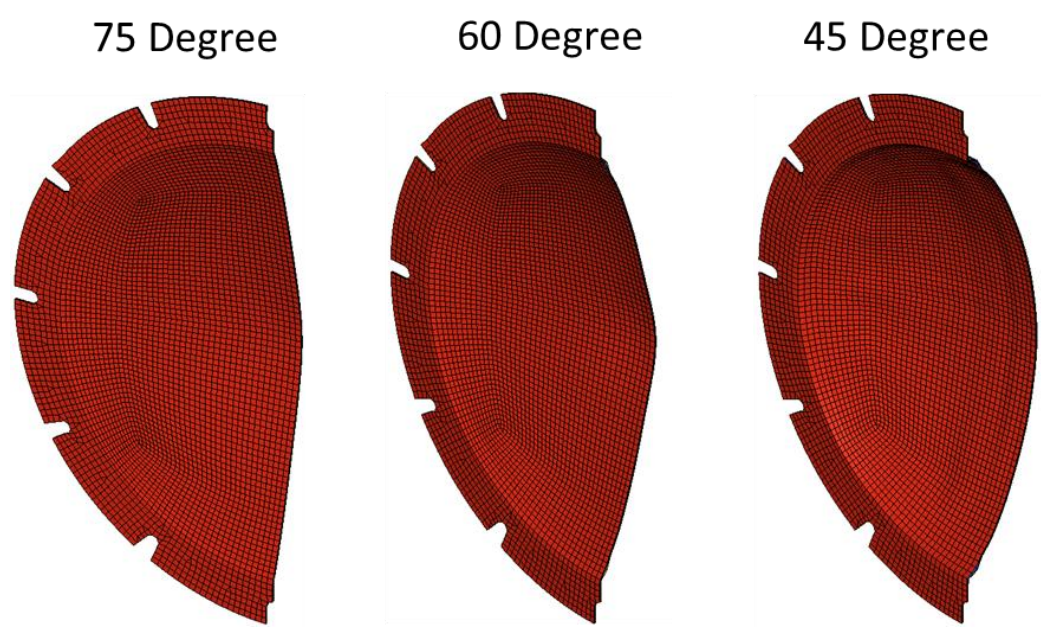

30 Degree

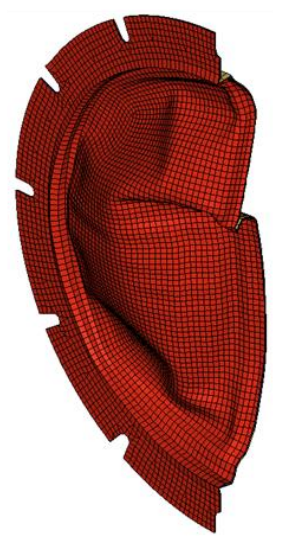

15 Degree

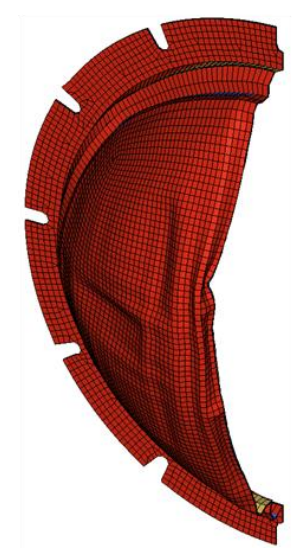

Figure 12 


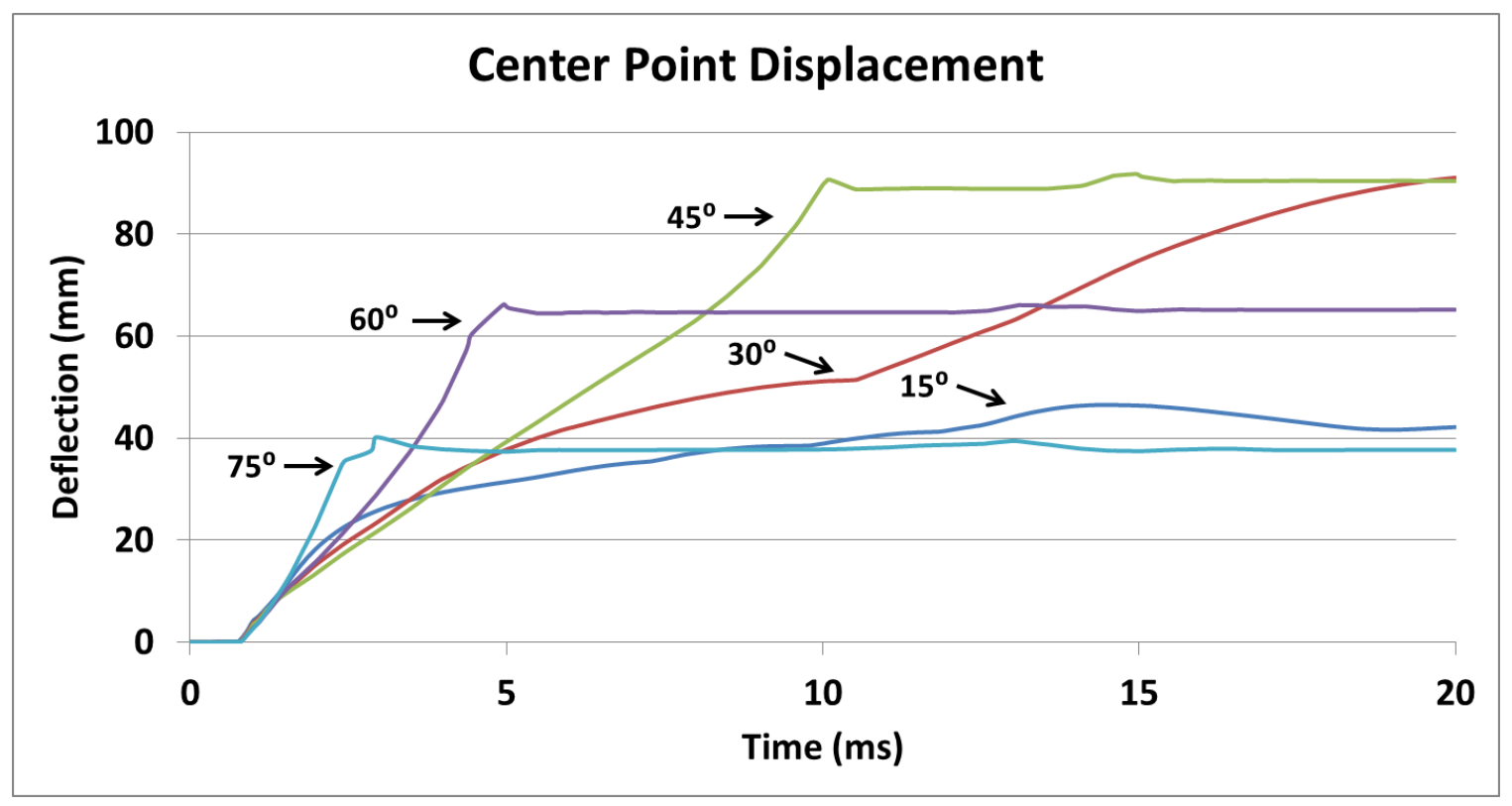

Figure 13 


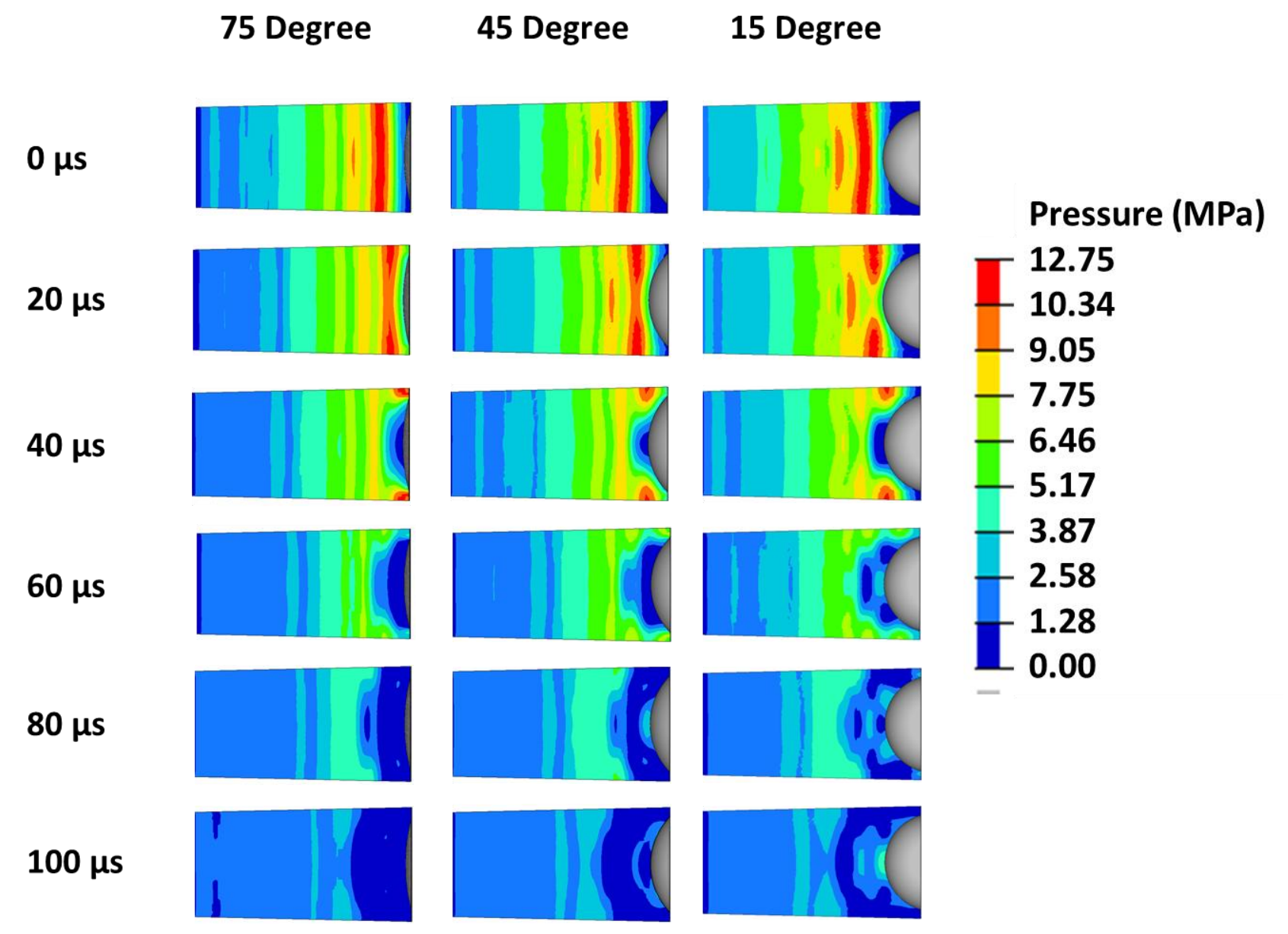

Figure 14 


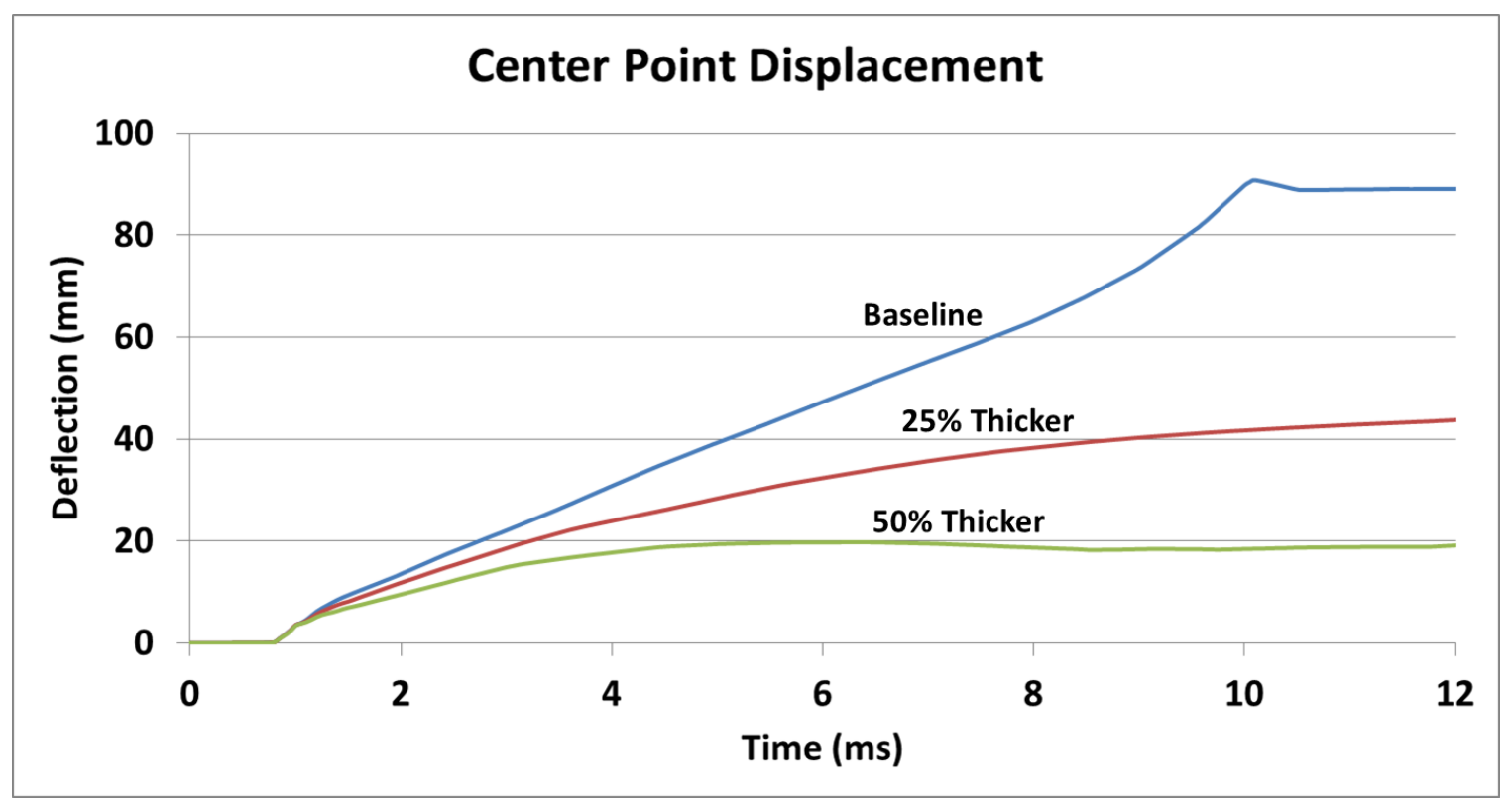

Figure 15 

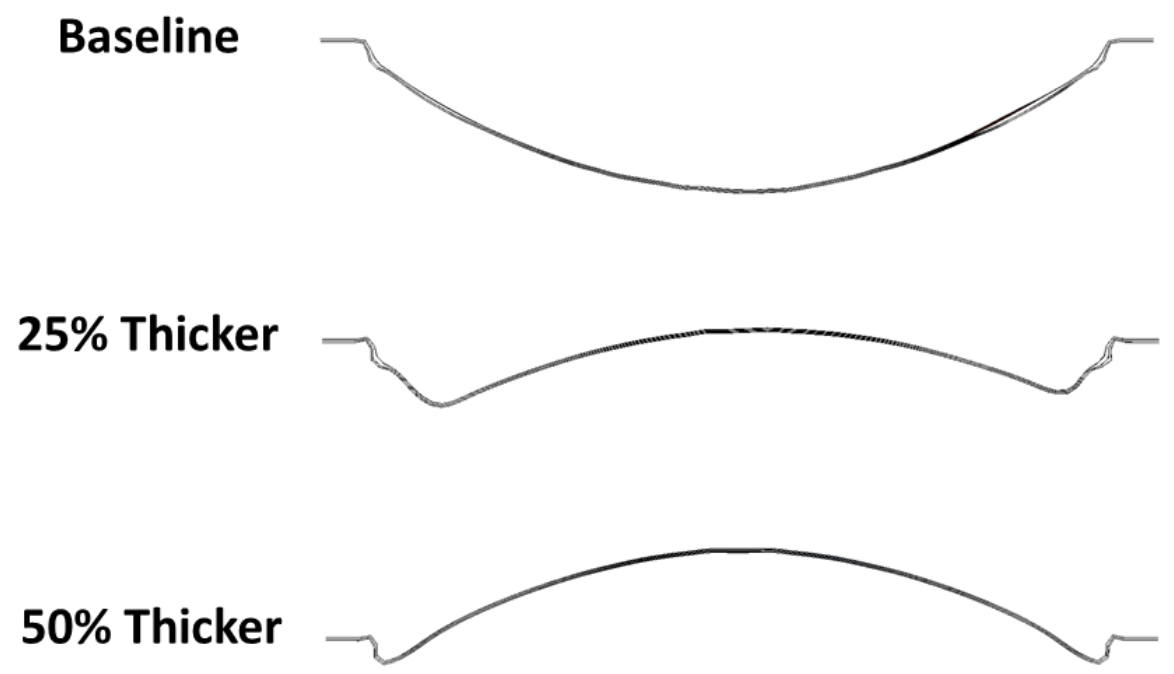

Figure 16 


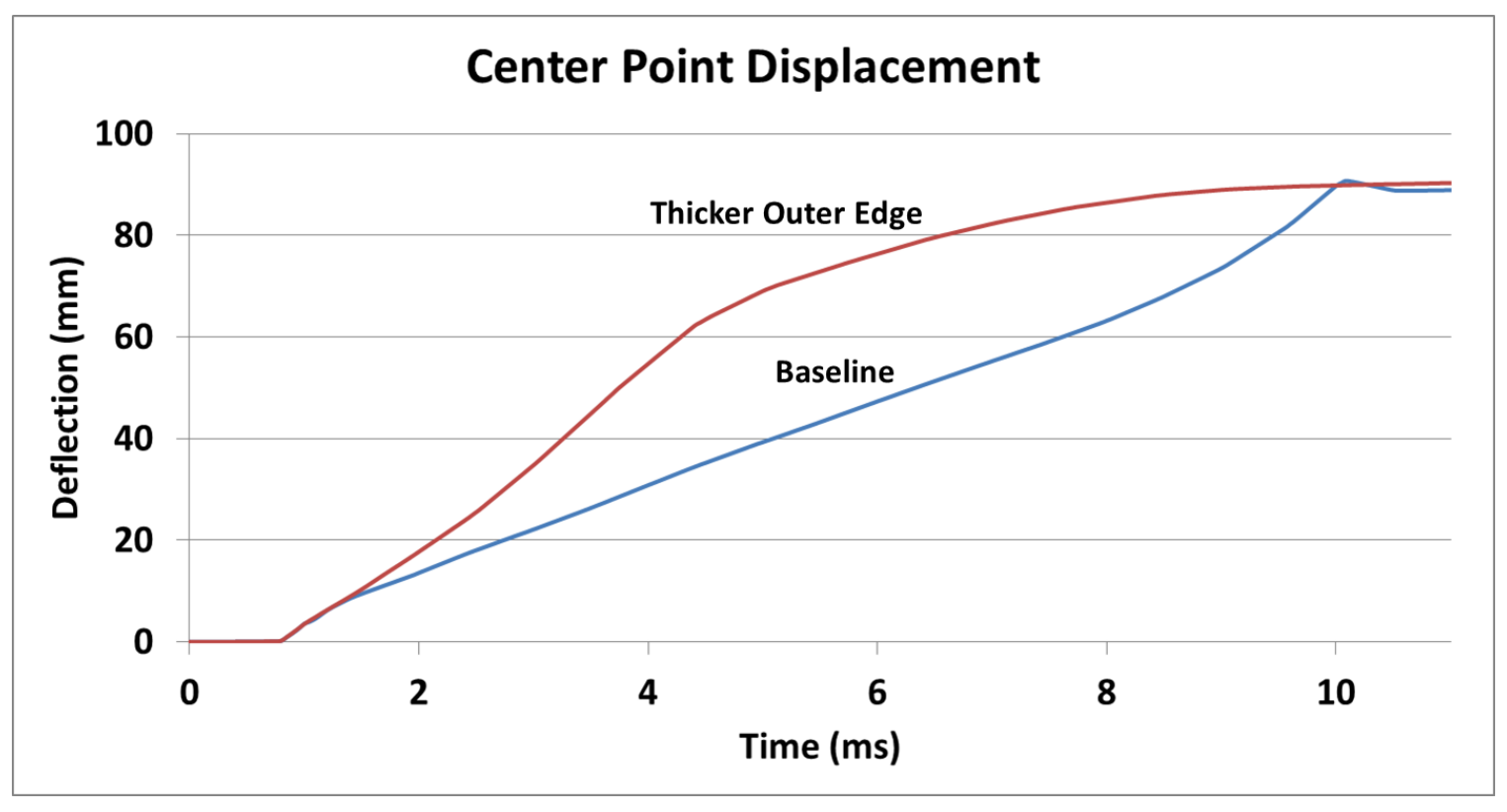

Figure 17 


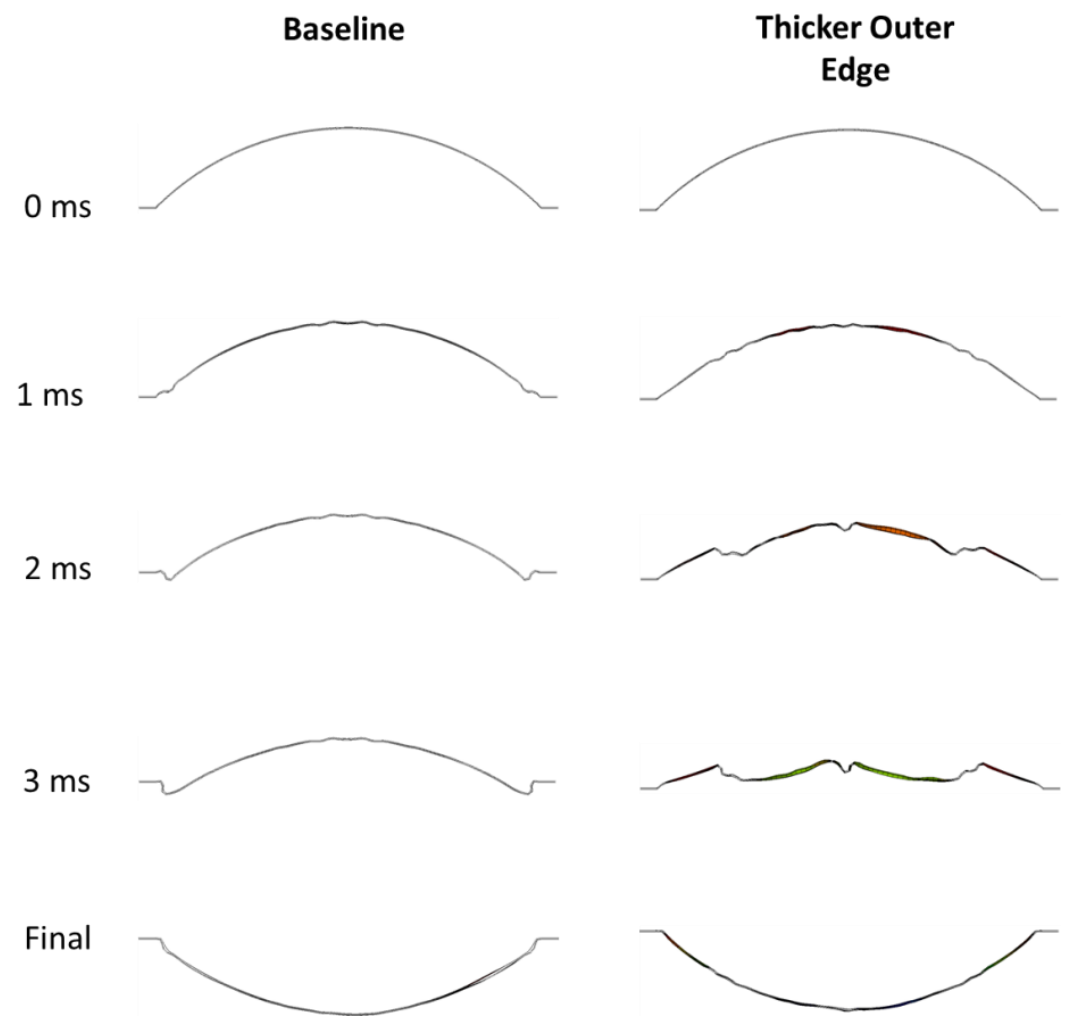

Figure 18 
Table 1

\begin{tabular}{|c|c|}
\hline & MPa $\left(\mathrm{lb} / \mathrm{in}^{2}\right)$ \\
\hline Tensile Modulus $\left(0^{\circ}\right)$ & $15.8 \mathrm{e} 3(2.3 \mathrm{e} 6)$ \\
\hline Tensile Modulus $\left(90^{\circ}\right)$ & $15.8 \mathrm{e} 3(2.3 \mathrm{e} 6)$ \\
\hline Tensile Strength $\left(0^{\circ}\right)$ & $324(47,000)$ \\
\hline Tensile Strength $\left(90^{\circ}\right)$ & $324(47,000)$ \\
\hline
\end{tabular}

